\title{
CLOUDSAT AND CALIPSO WITHIN THE A-TRAIN Ten Years of Actively Observing the Earth System
}

\author{
Graeme Stephens, David Winker, Jacques Pelon, Charles Trepte, \\ Deborah Vane, Cheryl Yuhas, Tristan L’Ecuyer, and Matthew Lebsock
}

More than 10 years of observations jointly collected by CloudSat and CALIPSO satellites have resulted in new ways of looking at aerosol, clouds, and precipitation, and new discoveries about processes that connect them.

$\mathrm{T}$ he International Geophysical Year (IGY) in $1957 / 58$ was a watershed moment in Earth sciences. It brought together many disciplines and marked a major change in the study of Earth. What evolved out of the IGY was an appreciation that

AfFILIATIONS: StePHENS-Jet Propulsion Laboratory, California Institute of Technology, Pasadena, California, and Department of Meteorology, University of Reading, Reading, United Kingdom; Winker AND TREPTE-NASA Langley Research Center, Hampton, Virginia; Pelon-Laboratoire Atmosphères, Milieux, Observations Spatiales, UPMC-UVSQ-CNRS, Paris, France; VANE AND LeBSOCKJet Propulsion Laboratory, California Institute of Technology, Pasadena, California; YUHAs-NASA Headquarters, Washington, D.C.; L'ECUYER-Department of Atmospheric and Oceanic Sciences, University of Wisconsin-Madison, Madison, Wisconsin CORRESPONDING AUTHOR: Graeme Stephens, graeme.stephens@jpl.nasa.gov

The abstract for this article can be found in this issue, following the table of contents.

DOI:10.II75/BAMS-D-16-0324.I

In final form 3 August 2017

C)2018 American Meteorological Society

For information regarding reuse of this content and general copyright information, consult the AMS Copyright Policy.
Earth was a dynamic system exemplified by the revolutionary new, emerging model of Earth plate tectonics. Dramatic advances in oceanic and atmospheric sciences also occurred during this period. We saw a deeper appreciation of the importance of the global interactions between oceans and the atmosphere and, more recently, the appreciation for the importance of interactions and feedbacks between land and atmosphere and the role of biogeochemical cycles. Today we fully understand and embrace the concept of an Earth system that is complex with interactions occurring between its many components.

The evolution of Earth system science is reflected in the increasing complexity of climate models and their evolution to Earth system models over time. It also has profound implications when contemplating an approach to observe the evolving Earth system. First, the broad realization has emerged that greater confidence in climate projections requires improved understanding of the processes that govern the feedbacks between Earth subsystems (e.g., Bony et al. 2015). This calls for a focus toward observing processes rather than making unconnected observations of individual variables. Second, the important processes, even very rapid processes like convection 
in the atmosphere, require monitoring over the long term in order to understand how these processes evolve on a slower trend of environmental change. While there is an unequivocal need for sustained long-term space-based observing systems (National Research Council 2015), such as those provided by operational satellites primarily designed for weather observations (e.g., Simmons et al. 2016), many of the most important Earth system processes involve subsystems not sufficiently observed by operational satellite systems. Thus, the challenge is to establish an affordable and implementable cross-disciplinary strategy that can deliver observations of the most critical Earth system processes and that can sustain these observations over the longer term. Despite the well-understood limitations of the existing operational systems, this strategy ought to draw benefit from, and build on, the core observations produced by operational meteorological satellites.

The challenge to observe the interactive Earth system has been recognized for some time. Making joint measurements of multiple parameters on one platform was the motivation of the Earth Observing System (EOS) platforms (Asrar and Dozier 1994), originally referred to as EOS-A and EOS-B and now referred to as Terra and Aqua, respectively. With the joint launch of the National Aeronautics and Space Administration (NASA) CloudSat (Stephens et al. 2008) and the NASA-Centre National d'Études Spatiales (CNES) Cloud-Aerosol lidar and Infrared Pathfinder Satellite Observations (CALIPSO; Winker et al. 2010) satellites on 28 April 2006, a W-band cloud-profiling radar (CPR) and a 530- and 1060-nm backscatter aerosol lidar [Cloud-Aerosol Lidar with Orthogonal Polarization (CALIOP)] were introduced to the A-Train constellation. This provided the constellation with two active remote sensors ${ }^{1}$ to complement the existing passive sensors of Aqua and Aura. The concept of an integrated observing constellation then flourished with a desire to explore linkages between and among many of the sensors across the A-Train satellite platforms (Stephens et al. 2002), thus demonstrating a new cross-disciplinary observing paradigm based on distributed observing systems.

CloudSat and CALIPSO, and NASA's Tropical Rainfall Measurement Mission (TRMM; Kummerow et al.2000) before them, clearly proved the viability of

\footnotetext{
${ }^{1}$ Active remote sensors detect the electromagnetic radiation returned back to the sensor typically from an artificial fixed pulse of radiation. Passive remote sensing is based on interpreting the natural levels of radiation scattered and/or emitted from Earth.
}

long-term active measurements of Earth and the fundamental importance of vertical profile information for understanding processes of the atmosphere. The CloudSat and CALIPSO missions also demonstrated coordinated formation flying in the A-Train constellation, which made the development of integrated products possible. This 10 -yr accomplishment was recently celebrated at a CALIPSO-CloudSat meeting in Paris, France, on 9-11 June 2016. This paper reviews the remarkable progress that has occurred since the launch of these two missions, each of which has resulted in almost 2,000 peer-reviewed publications. The paper provides, for the first time, the historical evolution of the A-Train and records the performance of both active sensors over 10 years. An iconic example of the new information provided by these profiling instruments is provided in the section "New capabilities in observing clouds, aerosol, and precipitation." The section "A new CloudSatCALIPSO interpretation of clouds" highlights how this information is now changing the way we looked at clouds in the past. The section "Process-level understanding" provides selected examples of how these data, either separately or when combined with other sensors, provide rich insights into important Earth system processes.

\section{THE EVOLUTION OF THE A-TRAIN CONSTELLATION. A pictorial depiction of the} evolution of the A-Train is offered in Fig. 1. The formation of the A-Train began with the launches of the NASA Aqua satellite in 2002 and the Aura satellite in 2004. Aura was placed several minutes behind Aqua in orbit, and this orbit was later adjusted to optimize overlap with CALIPSO and CloudSat observations. A few months after the Aura launch, on 18 December 2004, the French organization CNES launched the Polarization and Anisotropy of Reflectances for Atmospheric Sciences Coupled with Observations from a Lidar (PARASOL) satellite carrying the Polarization and Directionality of the Earth's Reflectances (POLDER) instrument and maneuvered PARASOL into orbital position between Aqua and Aura. CloudSat and CALIPSO were inserted between Aqua and Aura when they were launched in 2006. PARASOL was positioned to optimize measurement synergies with CALIPSO. The Orbiting Carbon Observatory (OCO) and the Glory satellites were both intended to join the A-Train, but in both cases the launches failed, OCO on 24 February 2009 and Glory on 4 March 2011. These major disappointments were followed with the successful launch of the Global Change Observation Mission-Water (GCOM-W1) of the Japan Aerospace 
Exploration Agency (JAXA), which entered the A-Train on 29 June 2012. PARASOL shifted to a lower orbit on 2 December 2009 and is no longer orbiting within the A-Train. CloudSat temporarily left the A-Train in 2011 as a result of a spacecraft battery failure and then returned to the A-Train but behind CALIPSO on 15 May 2012. It is acquiring data now in a daylight-only mode to the spacecraft battery loads.

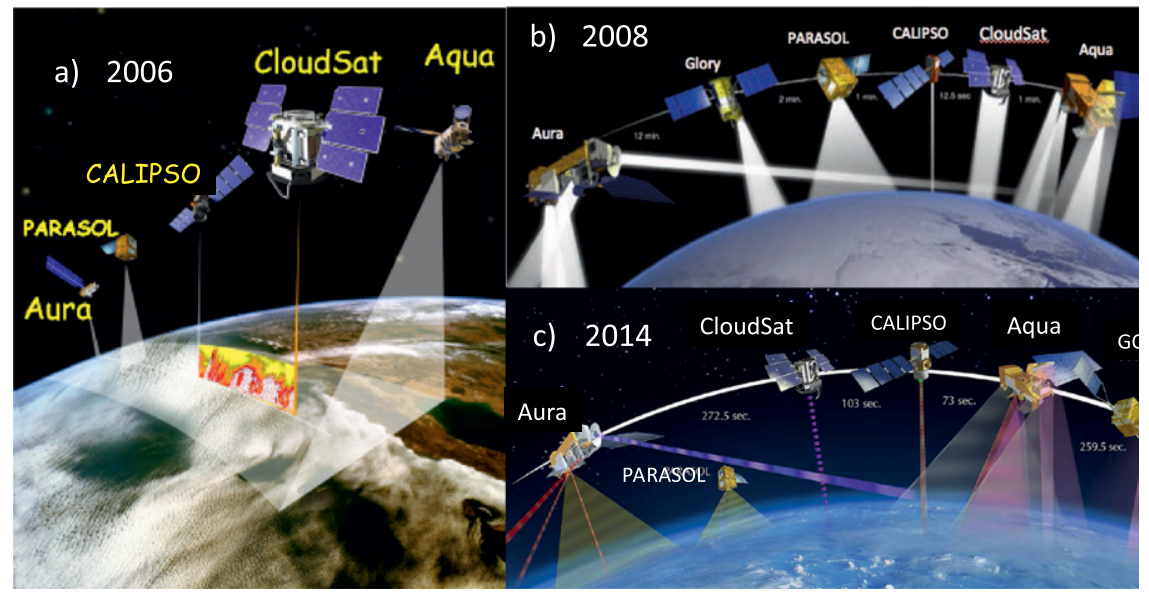

FIG. I. (a)-(c) Three depictions of the A-Train illustrating how it has evolved over time. The current A-Train configuration is shown in (c). OCO-2 was launched on 2

July 2014 and reached its assigned position at the head of the A-Train in front of GCOM-W1 a month later in a position overlapping with CALIPSO and CloudSat. As of 2016, the A-Train consists of six satellites arranged in the formation shown in Fig. 1c. Although each satellite is independently operated, their operation is carefully coordinated, with each satellite member committing to two principles that are maintained with regular reviews: 1) joint safety of constellation operations and 2) open sharing of science data.

\section{CLOUDSAT-CALIPSO INSTRUMENT} PERFORMANCES. Although the precipitation radar on TRMM had provided more than 8 years of data, the prelaunch lifetime expectation of both the $\mathrm{CPR}$ and CALIOP was conditioned by concerns that active systems were much less robust than passive sensors and could not be expected to operate for the same length of time. For CALIOP, these concerns were heightened by the failure of one of the lasers on board the Ice, Cloud and Land Elevation Satellite (ICESat) that occurred at the time the CALIOP lasers were being fabricated. Both the CPR and CALIOP instruments incorporated redundancies in design to mitigate these concerns. The CPR design includes redundant high-power amplifiers (HPA), each consisting of a high-voltage power supply coupled to an extended interaction klystron (EIK). The EIK had never flown in space nor had the voltages required to deliver the radar sensitivity been achieved in a space environment. The expectation was that a switch from one HPA to the other would be required after a few years of operations. Figure 2a provides an indication of the performance of the HPA over its current 10-yr lifetime, expressed in terms of the change in output power of the radar. This output power has degraded very slowly at about a rate of $0.2 \mathrm{~dB} \mathrm{yr}^{-1}$ between 2012 and 2014, but more recently the degradation appears to have increased to approximately $0.5 \mathrm{~dB} \mathrm{yr}^{-1}$. Ten years after the initial turn on, however, the CPR HPA redundancy has not been used, although the recent drop in output power is being carefully monitored and a switch to the redundant HPA is expected in the near future.

CALIOP was similarly designed with two redundant laser transmitters, each with a design lifetime of 3 years. A flight prototype underwent extensive life testing to verify the design approach. Both lasers were enclosed in pressurized containers and filled with dry air as a means of reducing the risk of optical damage caused by contaminants. The first laser operated for nearly 3 years before being turned off when operation became erratic because of low pressure caused by a slow leak in the canister. The second laser has operated since March 2009 and continued to operate near full power until the summer of 2017, when it began to fail. As of this writing, the CALIPSO team is planning to switch back to the first laser for further operation. Figure $2 \mathrm{~b}$ shows CALIOP's laser pulse energy has varied less than $20 \%$ since the beginning of the mission. The sudden increase in early 2009 represents the switch from primary to secondary lasers. These small variations have a negligible influence on instrument sensitivity. The time series of integrated 532-nm backscatter from 35 to $40 \mathrm{~km}$, which is dominated by molecular scattering, indicates the calibration scheme compensates for the laser pulse energy variations.

\section{NEW CAPABILITIES IN OBSERVING CLOUDS, AEROSOL, AND PRECIPITATION.}

In many respects, Fig. 3 is an iconic depiction of the atmosphere made possible only through 
the combined lens of the CloudSat radar and the CALIPSO lidar. The figure is a unique view of aerosol, clouds, and precipitation in the form of zonal averages of properties. The figure presents the cloud liquid water and ice contents, the latter of which is derived from the multiyear CloudSat and CALIPSO Ice Cloud Property Product (2C-ICE; Fig. 3a). The multiyear zonally averaged frequency of occurrence of precipitation by type (Fig. 3b), the zonally averaged vertical distribution of aerosol in terms of aerosol extinction for April 2010 (Fig. 3c), and the vertical profiles of the occurrence of clouds (Fig. 3d) and precipitation (Fig. 3e) are also presented for contrast. The zonal aerosol extinction offers hints at the boundary layer structure and bulk transports into the free troposphere in tropical regions, where deep convection resides (exemplified by the deep cloud occurrence regions in Fig. 3d). This aerosol information offers a way of testing model assumptions about both sources of aerosol and their transport (Winker et al. 2010).
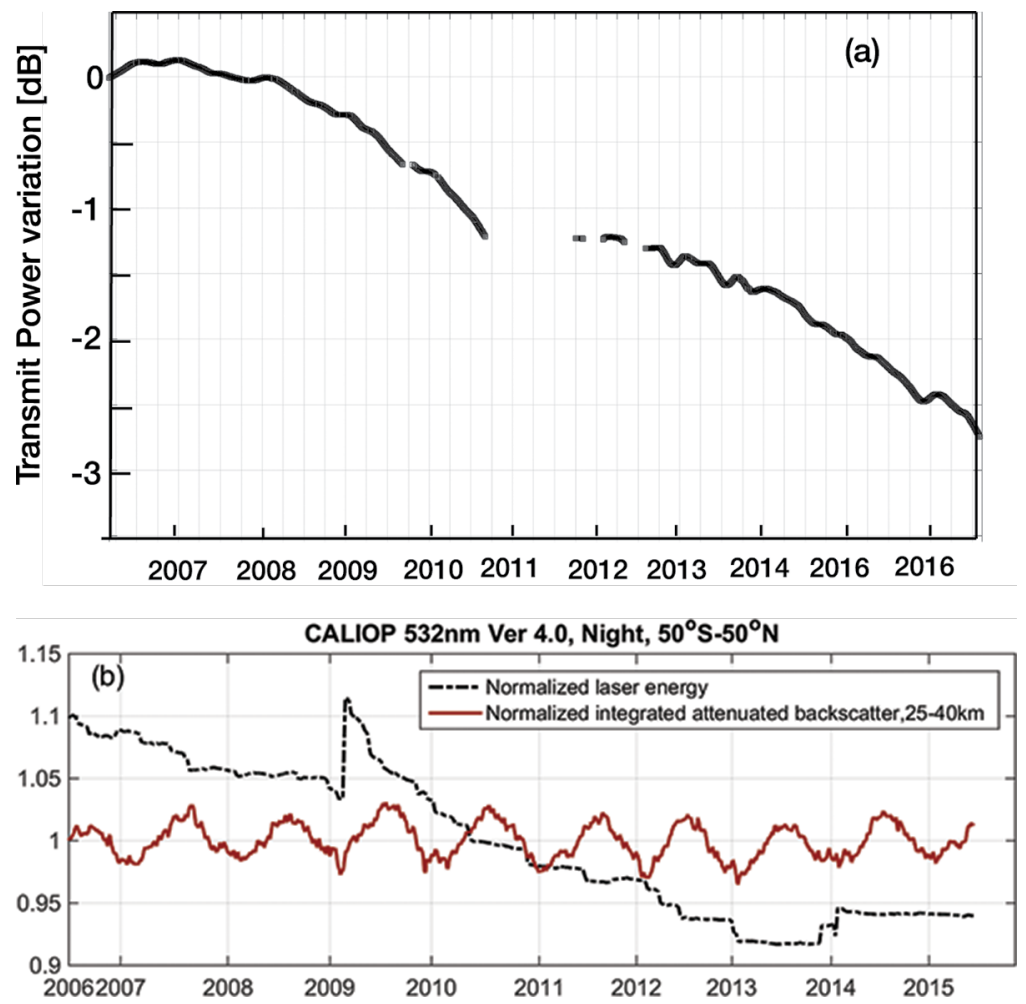

Fig. 2. (a) Best estimate of the evolution of the CPR transmit power from first day of operations until Julian day 316 of 2016, derived from a combination of output from the pulse detector and the surface reflection from all available clear-air observations. The power is scaled between 0 (beginning of mission) and -4 , which roughly corresponds to -30 - to $-26-\mathrm{dBZ}$ sensitivity. (b) Normalized trends of laser total pulse energy and midstratospheric 532-nm backscatter signals through mid-2015. The annual cycle seen in the backscatter time series reflects changes in molecular density caused by seasonal variations in stratospheric temperature.
Precipitation systems are much deeper on average in the tropics (Fig. 3e), and the frequency of precipitation is strongly enhanced in middle and higher latitudes, where snowfall becomes the more prevalent mode of precipitation poleward of about $60^{\circ} \mathrm{N}$ and $60^{\circ} \mathrm{S}$ (Fig. 3b). The resolved profiling of clouds and aerosol introduced by the CALIPSO-CloudSat combination now provide us with a much more refined picture tor of global precipitation currently in space today. It is capable of detecting the presence of a wide range of precipitation, from the lightest drizzle and snow to very intense, heavy convective rainfall, and offers our most definitive measure of precipitation occurrence. Precipitation detection is provided in the Level $2 \mathrm{C}$ precipitation column algorithm (2C-COLUMNPRECIP) product (Haynes et al. 2009), offering detection of precipitation over land and ocean (Smalley et al. 2014), including a phase determination (rain, mixed, and snow) based on the maximum tropospheric temperature in the CloudSat observation profile. The precipitation occurrence is determined using the reflectivity profile of the lowest discernible cloud layer, after correction for attenuation (e.g., Haynes et al. 2009).

The first global annual distribution of the frequency of occurrence of all forms of precipitation is provided in Fig. 4. The data are a 4-yr annual-mean frequency of occurrence of two classes of rain, namely, a drizzle category for the rain identified with reflectivities less than $0 \mathrm{dBZ}$ and rain representing all other cases, as well as the occurrences of snow and mixed-phase precipitation. The latter category is more of an indicator of uncertainty in the phase determination, and the relatively high frequency of this category points to the need for improved observations. These maps identify features of the atmospheric hydrologic cycle hitherto undetected. For example, the observation of the preponderance of drizzle and light rain along the eastern margins 
(a)

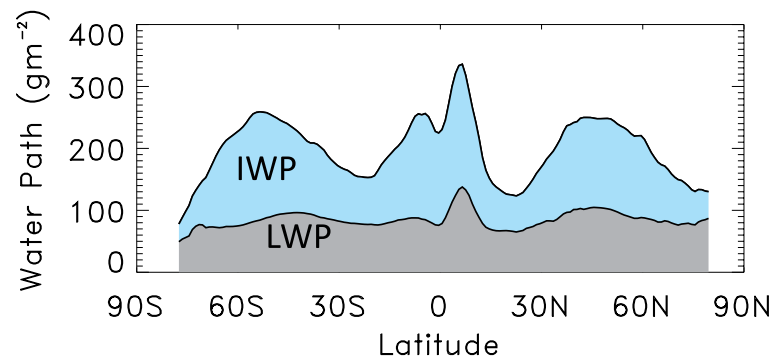

(c)

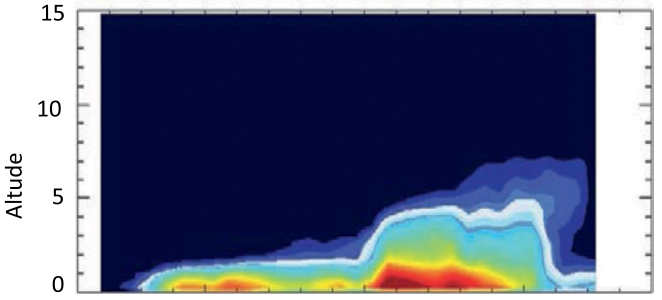

(d)
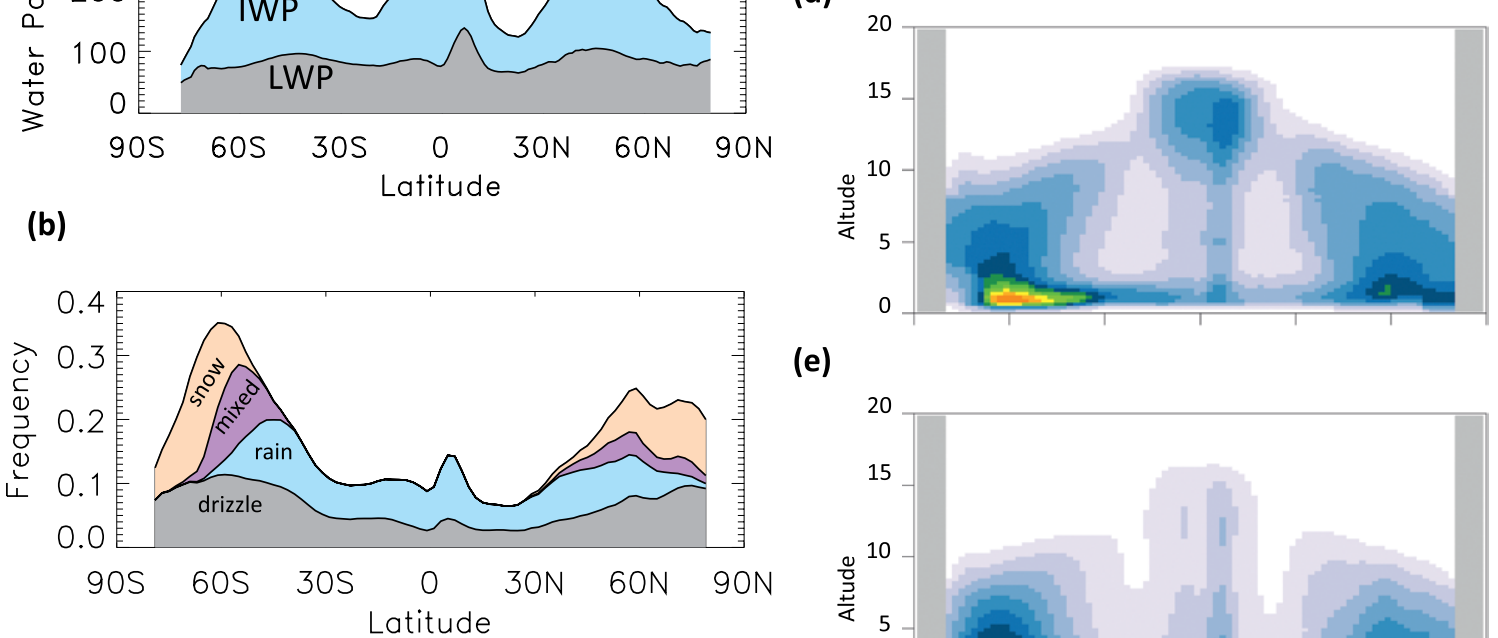

(e)

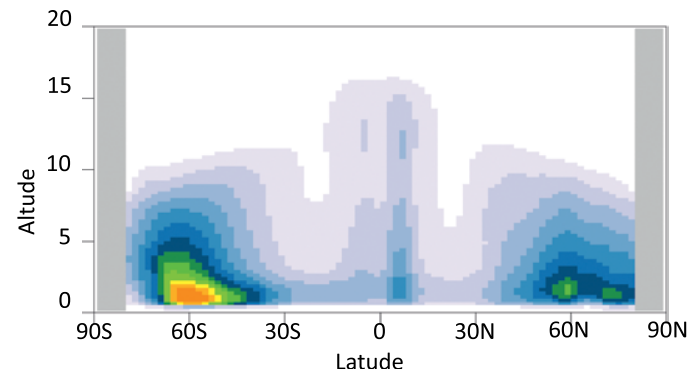

Fig. 3. (a) A multiyear annual zonal-mean liquid water path (gray shading, ocean only; $O$ 'Dell et al. 2008) and ice water path (blue shading, from CloudSat 2C-ICE dataset for 2006-10). (b) A multiyear annual-mean precipitation fractional occurrence from CloudSat 2C-COLUMNPRECIP. (c) The zonally averaged aerosol extinction from CALIOP under clear-sky conditions (from Winker et al. 2010) for April 2010. (d),(e) Multiyear latitude-height sections of annual zonal-mean cloud (including precipitation falling from cloud) occurrence and precipitation (attenuation-corrected radar reflectivity $>0 \mathrm{dBZ}$ ) occurrence; the latter has been doubled to make use of a common color scale [CloudSat geometric profile product (2B-GEOPROF)-lidar dataset].

of the subtropical oceans and in the midlatitude storm tracks, along with any meaningful detection of snow, had been previously lacking in other precipitation observations. It is also remarkable how little drizzle occurs over land in contrast to that over oceans (e.g., Takahashi et al. 2017).

\section{A NEW CLOUDSAT-CALIPSO INTERPRETA-} TION OF CLOUDS. Although cloud and aerosol information has been collected from Earth-orbiting satellites over many decades, the new dimension of CloudSat and CALIPSO together is now exposing biases in the interpretation of past passive observations (e.g., Mace and Wrenn 2013) while offering entirely new information about clouds and aerosol and the connections between them. Figure 5 is an example of how our past interpretation of radiance data has changed in light of the new profile information. Figure $5 \mathrm{a}$ is a two-dimensional (2D) radiance histogram representation of clouds that was introduced as an analysis tool as part of the International Satellite Cloud Climatology Project (ISCCP; Rossow and Schiffer 1999). The version of this histogram presented in Fig. 5a is a slightly modified version of the original 2D ISCCP histogram (Hartmann et al. 1992). In this instance, clouds are classified into five types according to their radiometric brightness temperatures (interpreted as cloud height) and visible brightness (interpreted as optical depth). Figure 5b is an analogous version of this histogram where now the cloud-top height is unambiguously defined using the CloudSat-CALIPSO data (Mace and Zhang 2014) and is placed into the equivalent height bins as the ISCCP analysis. The $x$ axis defines thin and thick clouds based on the water and ice content of clouds, which is directly proportional to the cloud optical depth, thus directly analogous to the categorization of thin and thick clouds in Fig. 5a. In this second 


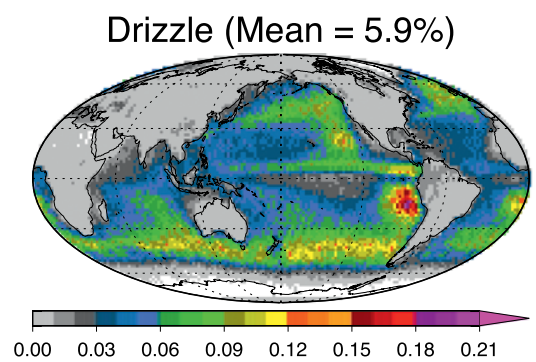

Fractional precipitation occurrence
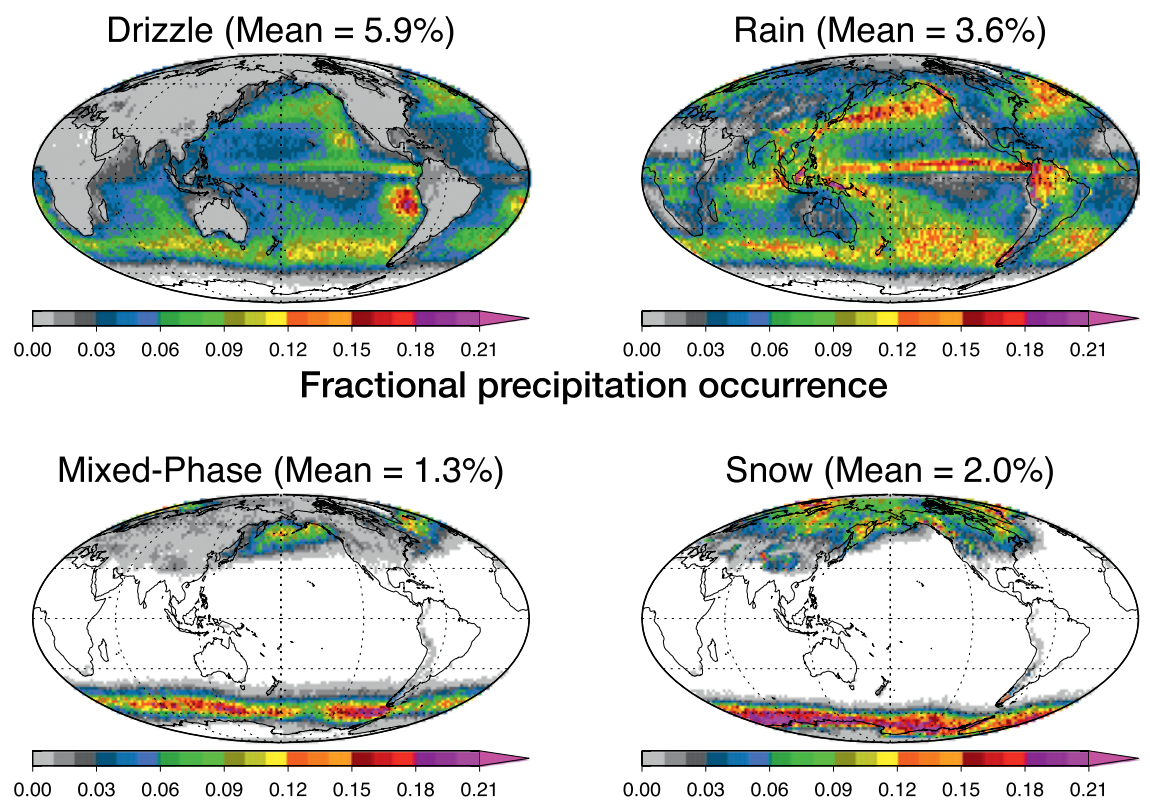

Fractional precipitation occurrence

FIG. 4. The global occurrence of various modes of precipitation. (top left) Drizzle is categorized by radar reflectivities less than about $-10 \mathrm{dBZ}$. (top right) Rain represents all other warm precipitation cases. (bottom left) Mixedphase precipitation is categorized by near-surface temperatures between $2^{\circ}$ and $4^{\circ} \mathrm{C}$ and should be interpreted as an uncertain phase category. (bottom right) Snow is assumed when the near-surface temperature is less than $2^{\circ} \mathrm{C}$.
5) and to a lesser degree from midlevel thick clouds (type 4). With more explicit cloud profile information, however, the net radiative effect of clouds is now much less dominated by low clouds and appears as more a mix of effects from low, midlevel, and multilayered clouds.

The profiling capabilities have also provided an invaluable tool to assess and calibrate other radiance data. The ambiguity of the ISCCP height assignment in part stems from the ambiguity in interpretation of a single-channel IR radiance, whereas much better height characterization is possible when more spectral information is used, as exemplified in a number of studies based on Atmospheric Infrared Sounder example, not only do the profile data place clouds at their correct heights, but the main difference is that the profile information from the radar-lidar now identifies multilayered cloud systems, which occur about $60 \%$ of the time clouds are observed (Stephens et al. 2008). These multilayered categories, consisting mostly of high clouds over low clouds, are mostly missing in the radiance-based classification. These multilayered cases fall into the type- 2 classification because the heights of the upper cloud layers identify them as high clouds, but they appear as optically thick clouds because this classification includes the combination of optical thickness from the multiple layers. Figures $5 c$ and $5 d$ are the respective estimates of the June-August (JJA) and December-February (DJF) seasonal net cloud radiative effects (CREs) associated with each cloud type of the Hartmann et al. analysis, and Figs. 5e and $5 \mathrm{f}$ are the corresponding CREs derived from the recent A-Train analysis. The differences between these two pairs of results highlight how the cloud-height ambiguity inherent to passive observations misleads the assignment of radiative effects by cloud type. For example, the Hartmann et al. analysis concludes that the dominant source of large negative net CRE in midlatitudes arises primarily from the shortwave reflection from low clouds (type
(AIRS) data (Kahn et al. 2014; Stubenrauch et al. 2008). CloudSat and CALIPSO data have also been used as tools to tune other satellite observations, such as microwave methods for retrieving snowfall (e.g., Liu and Seo 2013; Kulie et al. 2016), thin ice cloud optical depths from the Moderate Resolution Imaging Spectroradiometer (MODIS; Heidinger et al. 2015), and geostationary observations (Kox et al. 2014).

\section{PROCESS-LEVEL UNDERSTANDING. Super-} cooled clouds of the Southern Ocean. Incorrect characterization of cloud phase has long been identified as a potential source of uncertainty in climate models and associated cloud-climate feedbacks (Mitchell et al. 1988; Li and Le Treut 1992; Tan et al. 2016) and a long-standing reflected shortwave radiation model bias over the southern oceans (Trenberth and Fasullo 2010). CALIOP depolarized backscatter is an unambiguous indicator of the phase of water in clouds in the vicinity of cloud top (Hu et al. 2009). This observation provided the clue to the persistent Southern Ocean cloud bias that is now identified to be caused by a lack of supercooled water in modeled clouds in the cold sector of baroclinic weather systems (BodasSalcedo et al. 2014; Forbes and Ahlgrimm 2014; Bodas-Salcedo et al. 2016; Kay et al. 2016; Forbes et al. 
2016). Bodas-Salcedo et al. (2016) use both CALIOP and CloudSat data to identify the zonal amounts of clouds of differing phase, revealing that virtually all liquid clouds are supercooled poleward of $48^{\circ} \mathrm{S}$. They further show that ice-topped clouds dominate the contribution to the top of the atmosphere (TOA) flux at all latitudes, except between $60^{\circ}$ and $65^{\circ} \mathrm{S}$, where supercooled liquid clouds reside and contribute significantly to the TOA reflected flux.

Figure 6 is an example of how the combination of CALIOP and CPR were used to tune model parameterizations to correct for a lack of supercooled clouds in the European Centre for Medium-Range Weather Forecasts (ECMWF) Integrated Forecast System (IFS; Forbes et al. 2016). Figures $6 \mathrm{~b}$ and $6 \mathrm{c}$ show specific IFS simulations of the CloudSat-CALIPSO alongtrack observations. A comparison of the operational version of IFS (Fig. 6b) to the observations (Fig. 6a) reveals great differences in cloud phase between the original operational model and the CALIOP observations. Changes to the model convection scheme, subsequently introduced and tuned, produce more liquid in clouds to match to the observations (Fig. 6c) over the Southern Ocean. This in turn resulted in the removal of most of the IFS shortwave reflected flux bias.

Warm rain processes. A-Train data have revealed new insights about the production of warm rain in clouds. Suzuki et al. (2010) combined cloud optical depth $\tau$ from reflected sunlight measurements of MODIS with the local volume scattering of radar, expressed in terms of the radar reflectivity $Z$, to provide direct insight into the coalescence process. Takahashi et al. (2017) use these measurements to contrast the warm rain processes in clouds over land versus ocean. Their major finding is summarized in Fig. 7, which shows the joint distributions of $\tau$ and $Z$ from nondrizzling clouds and clouds that form rain. This distinction is easily deduced from the radar observations given the acute sensitivity of $Z$ to cloud drop size. The figure shows profiles of reflectivity for nonraining and raining clouds over ocean (top panels) and over land (bottom panels). (a)

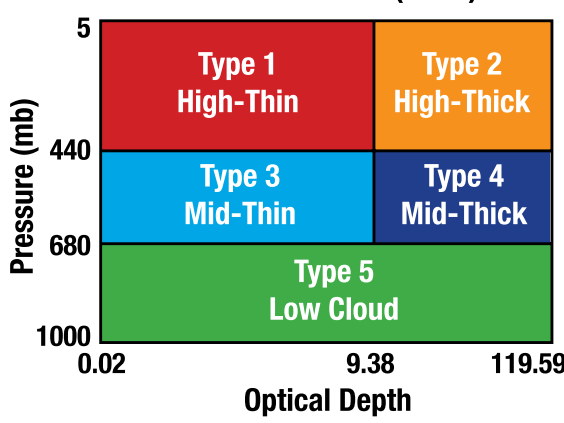

(b)

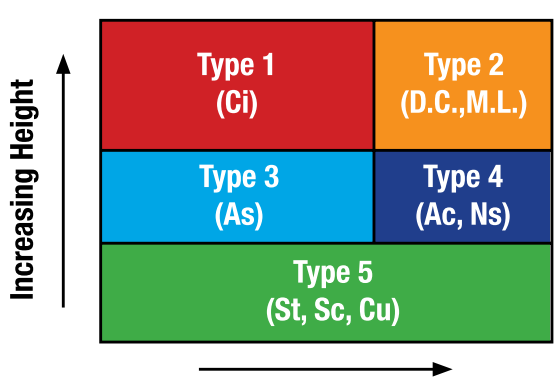

Increasing Optical Depth (c)

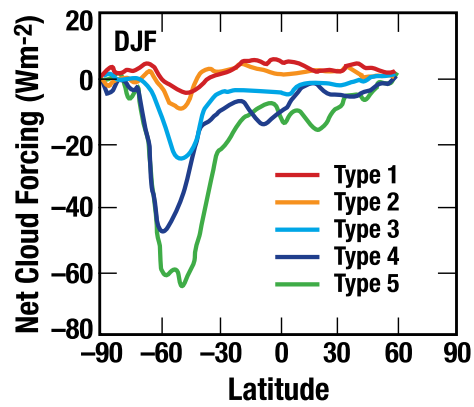

(e)

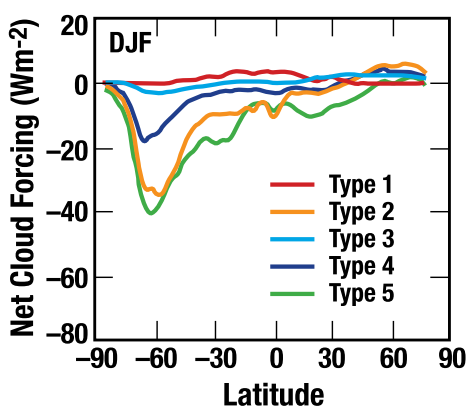

(d)

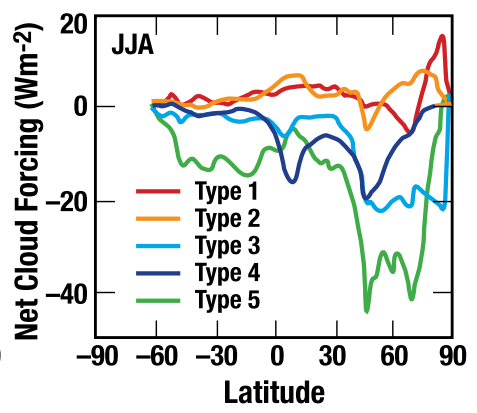

(f)

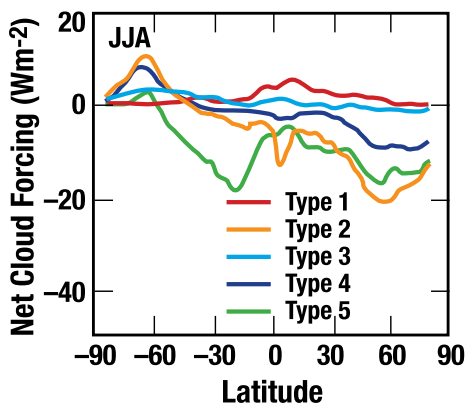

Fig. 5. (a),(c),(d) From Hartmann et al. (1992), who estimate the contribution to the CREs of five classes of clouds as defined according to the ISCCP radiance classification [(a)]. (b),(e),(f) As in (a),(c), and (d), but with classification determined by the radar-lidar data of CloudSat and CALIPSO, where true cloud heights establish the types and cloud thicknesses ( $x$ axis) are from water and ice path information, which is proportional to cloud optical depth. The differences in CRE between this latter analysis and that of Hartmann et al. underscore the effects of misclassification of clouds on the interpretation of their radiative effects. $\mathbf{C i}=$ cirrus, $\mathbf{D} . \mathbf{C} .=$ deep convection, $\mathrm{M} . \mathrm{L} .=$ multilayer, $\mathbf{A S}=$ altostratus, $\mathbf{A C}=$ altocumulus, $\mathbf{N S}=$ nimbostratus, $\mathbf{S t}=$ stratus, $\mathbf{S C}=$ stratocumulus, and $\mathrm{Cu}=$ cumulus. 

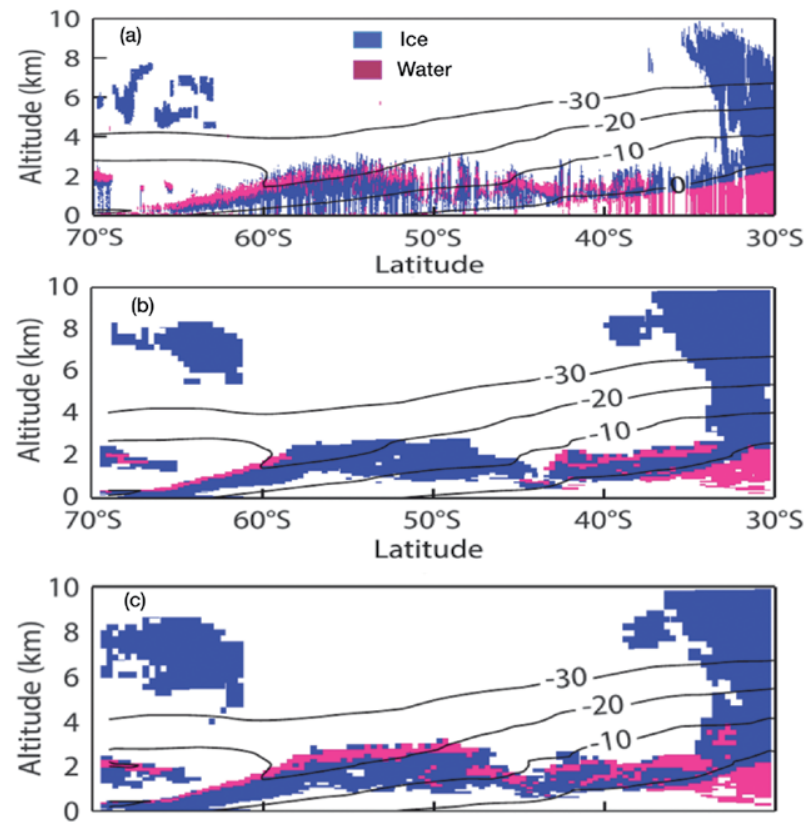

FIG. 6. Vertical cross section of cloud phase as given from (a) observations using a CloudSat-CALIPSO product. (b) ECMWF forecast model simulations with standard model physics. (c) Simulations with an experimental version of the forecast model with modified convective detrainment (Forbes et al. 2016). The legend denoting ice (blue) and water (red) is in (a).

The colored scale is expressed as a percentage of times a given reflectivity value occurs relative to the total number of reflectivity counts in any given $\tau$ bin. The schematic figures provide a corresponding cloud physical interpretation of the measurements. The results reveal that oceanic clouds had a higher fraction of tiny drizzle-size rain particles than their land-based counterparts, opposite of what has been generally thought to be true. It is believed that larger concentrations of aerosols over land would produce clouds composed of smaller drops, with the expectation that these clouds would drizzle more and rain less heavily than clouds formed with fewer but larger drops more typical of those over oceans. This simple argument is the basis of one of the main mechanisms proposed for how aerosol can affect clouds and Earth's climate through aerosol-cloud effects. But the results suggest other processes also determine how much clouds rain, and the study was able to use ground-based radar data to unravel the mystery. Shallow oceanic clouds have much weaker updrafts than analogous continental clouds. These stronger updrafts over land push the small drizzle droplets higher, making deeper clouds and larger raindrops form as they fall from higher in the cloud. This study clearly shows how understanding aerosol effects on clouds cannot be done without some understanding of cloud dynamics.

Snowfall and cryospheric processes. Palerme et al. (2017) used CloudSat snowfall data to guide an assessment of Antarctic cryospheric processes under different global warming scenarios. They find the historical simulations of Antarctic snowfall rate of models in phase 5 of the Coupled Model Intercomparison Project (CMIP5) archive overestimate current Antarctic precipitation, some by more than $100 \%$ compared to CloudSat snowfall. Only 13 of the 40 models analyzed simulated snowfall rates within $\pm 20 \%$ of CloudSat (Fig. 8a). When considering CMIP5 climate change experiments, the 40 models predicted an increase in Antarctic precipitation from $5.5 \%$ to $24.5 \%$ between 1986-2005 and 2080-99, depending on the assumed greenhouse gas emissions scenario. This translates into a moderation of future sea level rise ranging from -19 to $-71 \mathrm{~mm}$ between 2006 and 2099. If only the models that agree with CloudSat snowfall data within $20 \%$ are considered, then larger precipitation changes (from $7.4 \%$ to $29.3 \%$ ) and a larger impact on sea level (from -25 to $-85 \mathrm{~mm}$ ) are predicted. If one uses the present simulations as guidance, then the common practice of averaging all models to evaluate climate projections suggest that the contribution of Antarctic precipitation to future sea level will be underestimated. Since the precipitation and sea ice cover are negatively correlated (Palmere et al. 2017), these models that also predict heavier precipitation and larger impact on sea level also predict larger reductions in sea ocean cover (Fig. 8b).

Dust injection processes. The addition of aerosol vertical profiling from CALIOP has also advanced our aerosol remote sensing capabilities and our understanding of the global 3D distribution of aerosol (Winker et al. 2013). The additional ability of CALIOP to distinguish between depolarizing dust and nondepolarizing smoke and marine aerosols, combined with the aerosol profiling capability, provides new insights into the intercontinental transport of dust and smoke. This new capability results when the vertical profile of aerosol concentrations and the wind profile information are connected, providing a means to estimate dust mass fluxes with much greater confidence than possible from passive sensors. Thus, this new profile capability provides the means now to move from qualitative tracking of dense aerosol plumes to quantitative characterization of transport paths and mechanisms resolved by height and thus a more refined ability to evaluate model representation of these transports (e.g., Liu et al. 2008; Eguchi et al. 2009). 
An example of the use of CALIOP to examine the dust injection mechanisms that lift dust into the free troposphere where it can be carried by the largescale winds is illustrated in Fig. 9. In this example of Yumimoto et al. (2009), CALIOP data are used to trace a specific veil of dust that was lifted from the Taklimakan Desert in northwestern China and was transported over eastern Asia, the Pacific Ocean, North America, and the Atlantic Ocean, encircling Earth. A chemical transport model was used in conjunction with the observations to test ideas about the lifting mechanism that was determined to be a result of strong upslope winds along the high, steep mountainsides of the Tibetan Plateau. The presence of the mountains forces the dust-laden air high into the upper troposphere (to about $9 \mathrm{~km}$ above mean sea level) (MSL)], where it was transported by the strong westerlies at these upper levels. Yumimoto et al. argue that broad agreement with CALIOP extinction profile data, specifically the height location of the plume, verifies the lifting mechanism and the associated transport identified by the model.

CONCLUDING COMMENTS. The two principal sources of uncertainty in climate projections are due to uncertainties surrounding aerosol radiative forcings and the uncertainties attached to cloud feedbacks. The vertical distribution of aerosol significantly impacts these forcings, and the changes in the vertical distribution of clouds fundamentally affect the cloud feedbacks. Observation of the vertical structure of clouds is essential to unraveling these opposing feedback effects of high and low clouds. Profile changes are also predicted to be much larger than absolute changes in cloud cover and thus more readily detectible (e.g., Chepfer et al. 2014). Active remote sensing is the most direct way to obtain these observations.

During 10 years in orbit, both CloudSat and CALIPSO have demonstrated the viability of active systems for sustained monitoring of Earth's atmosphere. The 10 years of global profile data from these active sensors have profoundly changed our perspectives on the atmosphere in general and on the reliability of active observing systems. Profile data have exposed the limitations inherent in using radiance data to detect clouds, especially in polar regions, and the ambiguities in assigning heights, types, and properties to global clouds. Profile data on aerosols now offer new insights into how they are transported and mixed in the atmosphere and new insights into aerosol radiative forcing, and they have directly assisted in routine assimilation of aerosol informa-
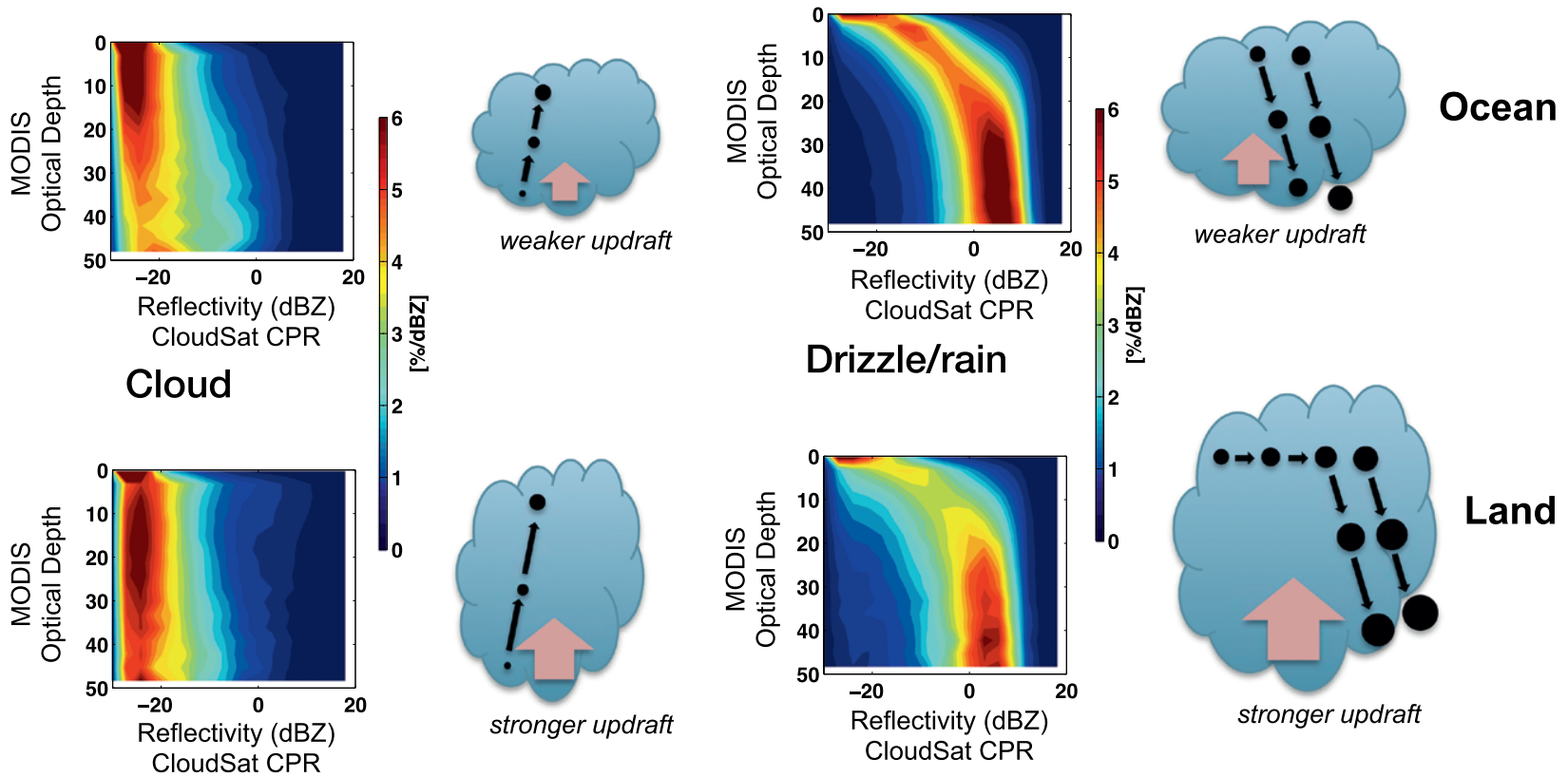

Fig. 7. Observed composite relations between optical depth measured downward from cloud top and radar reflectivity derived from 4 years of data separate for (top) oceanic clouds and (bottom) continental clouds and for (left) cloudy/nonraining cases and (right) drizzle/rain cases. The reflectivity range for clouds is approximately $Z<-15 \mathrm{dBZ}$, for drizzle $-15<Z<0 \mathrm{dBZ}$, and for rain $Z>0 \mathrm{dBZ}$; these profiles reveal information about cloudto-rain transitions in clouds. The schematics are for illustration and correspond to each composite profile result. The color scale refers to reflectivity counts as a percentage of total reflectivity occurrence within each given optical depth bin. Over land the drizzle mode is mostly missing (adapted from Takahashi et al. 20I7). 
tion. These active observations are nearing the end of their expected lifetimes and will soon be followed by the Earth Clouds, Aerosol and Radiation Explorer (EarthCARE; Illingworth et al. 2015). It is clear that active profile data are essential for the future monitoring of clouds and aerosols. What is missing is a way to transition these pioneering efforts into more routine and longer-term (and also more cost effective) measurements after EarthCARE is decommissioned in the 2022 time frame. These observations are not yet accepted in routine operational systems, but cloud profile information is now accepted as an essential climate variable under Global Climate Observing System (GCOS) of the World Meteorological Organization. The follow-on to CloudSat and CALIPSO was recommended under the previous National Research Council's 2007-17 decadal survey, but it was not an implemented mission, and the status of this mission concept and other follow-on concepts are being studied as part of the ongoing 2017-27 decadal study.
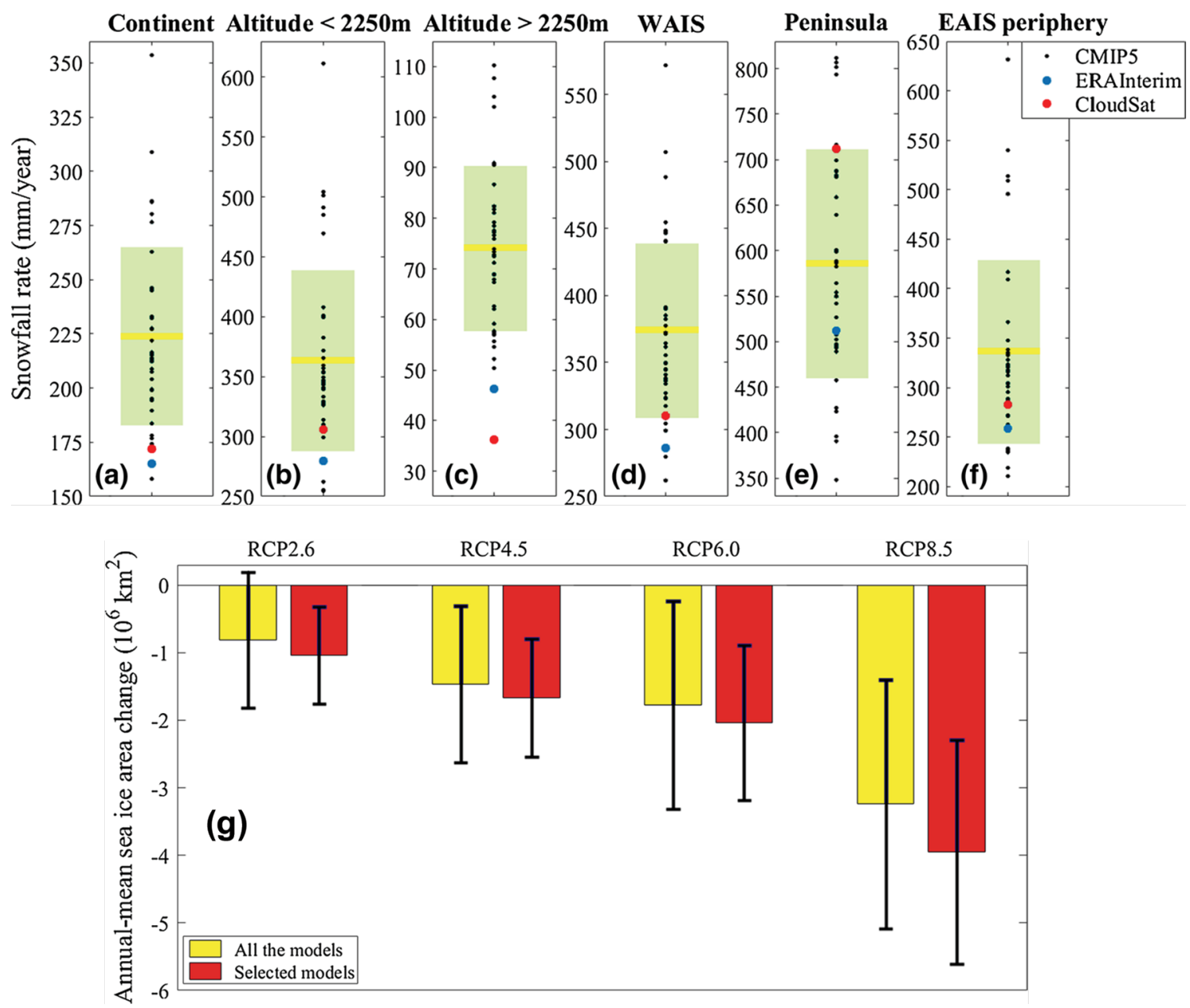

Fig. 8. (a)-(f) Mean annual snowfall rate ( $\mathrm{mm}$ water equivalent per year) during the period 1986-2005 for the CMIP5 models and ECMWF interim reanalysis (ERA-Interim), and during the period 2007-10 for CloudSat. (a) Antarctic continent (north of $82^{\circ} \mathrm{S}$ ). (b) Peripheral regions of the ice sheet with surface elevation lower than $2250 \mathrm{~m}$ (north of $82^{\circ} \mathrm{S}$ ). (c) High Antarctic plateau with surface elevation higher than $2250 \mathrm{~m}$ (north of $82^{\circ} \mathrm{S}$ ). (d) West Antarctic ice sheet (north of $82^{\circ} \mathrm{S}$ ). (e) Peninsula. (f) Peripheral areas of the East Antarctic ice sheet with surface elevation lower than $2250 \mathrm{~m}$ (north of $82^{\circ} \mathrm{S}$ ). The legend denotes CloudSat (red dots), ERA-Interim (blue dots), and CMIP5 climate models (black dots; historical scenario). The mean snowfall rate for all the CMIP5 models is indicated by the yellow bar, and the standard deviation is indicated by the green rectangle. (g) Annual-mean sea ice area changes in the Southern Hemisphere simulated by the CMIP5 models between the periods 1986-2005 in the historical scenario and 2080-99 in the four RCP scenarios (yellow bars). The annual-mean sea ice area changes for the models, which simulate a snowfall rate during the period 1986-2005 close to the CloudSat snowfall rate $(\mathbf{\pm 2 0 \%}$; red bars). The intermodel spread is denoted (error bars). 
FIG. 9. (a) Vertical longitudinal cross sections of the Spectral Radiation-Transport Model for Aerosol Species (SPRINTARS)simulated dust extinction coefficient along a Hybrid Single-Particle Lagrangian Integrated Trajectory model (HYSPLIT) trajectory. Large arrows show horizontal dust fluxes at $140^{\circ} \mathrm{E}, 130^{\circ} \mathrm{W}$, and $80^{\circ} \mathrm{W}$ estimated by SPRINTARS. The percentage in each bracket is the ratio of the dust amount to that exported to the Pacific through the $140^{\circ} \mathrm{E}$ meridian. (b) Normalized vertical profiles of the dust extinction coefficient measured by CALIOP (solid black lines) and simulated by RAMS/CFORS4DVAR model system (blue lines with solid circles) and SPRINTARS (red lines with triangles), along CALIOP orbits. The uncertainty of the CALIOP retrievals is denoted (horizontal error bars).

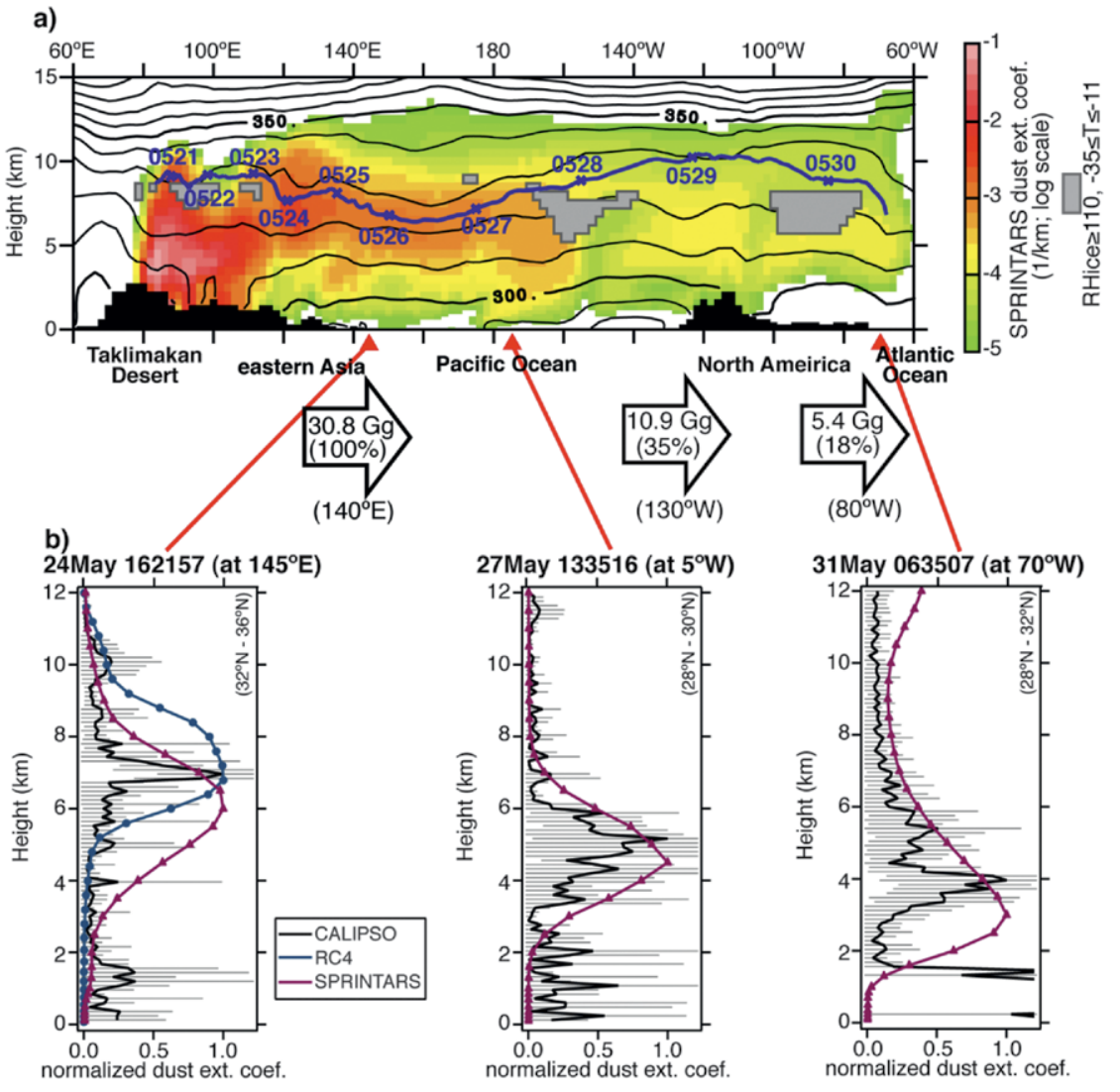

ACKNOWLEDGMENTS. This study was supported by NASA Grants NNN12AA01C and 1439268.

\section{REFERENCES}

Asrar, G., and J. Dozier, 1994: EOS: Science Strategy for the Earth Observing System. American Institute of Physics Press, 119 pp.

Bodas-Salcedo, A., and Coauthors, 2014: Origins of the solar radiation biases over the Southern Ocean in CFMIP2 models. J. Climate, 27, 41-56, https://doi .org/10.1175/JCLI-D-13-00169.1.

—, P. G. Hill, K. Furtado, K. D. Williams, P. R. Field, J. C. Manners, P. Hyder, and S. Kato, 2016: Large contribution of supercooled liquid clouds to the solar radiation budget of the Southern Ocean. J. Climate, 29, 4213-4228, https://doi.org/10.1175 /JCLI-D-15-0564.1.

Bony, S., and Coauthors, 2015: Cloud, circulation and climate sensitivity. Nat. Geosci., 8, 261-268, https:// doi.org/10.1038/ngeo2398.

Chepfer, H., V. Noel, D. Winker, and M. Chiriaco, 2014: Where and when will we observe cloud changes due to climate warming? Geophys. Res. Lett., 41, 8387-8395, https://doi.org/10.1002 /2014GL061792.
Eguchi, K., I. Uno, K. Yumimoto, T. Takemura, A. Shimizu, N. Sugimoto, and Z. Liu, 2009: TransPacific dust transport: Integrated analysis of NASA/CALIPSO and a global aerosol transport model. Atmos. Chem. Phys., 9, 3137-3145, https://doi .org/10.5194/acp-9-3137-2009.

Forbes, R. M., and M. Ahlgrimm, 2014: On the representation of high-latitude boundary layer mixedphase cloud in the ECMWF global model. Mon. Wea. Rev., 142, 3425-3445, https://doi.org/10.1175 /MWR-D-13-00325.1.

—, A. Geer, K. Lonitz, and M. Ahlgrimm, 2016: Reducing systematic errors in cold-air outbreaks. ECMWF Newsletter, No. 146, ECMWF, Reading, United Kingdom, 17-22, https://doi.org/10.21957 /s41h7q71.

Hartmann, D. L., M. E. Ockert-Bell, and M. L. Michelsen, 1992: The effect of cloud type on Earth's energy balance: Global analysis. J. Climate, 5, 1281-1304, https://doi.org/10.1175/1520-0442(1992)005<1281: TEOCTO $>2.0 . C O ; 2$.

Haynes, J. M., T. S. L'Ecuyer, G. L. Stephens, S. D. Miller, C. Mitrescu, N. B. Wood, and S. Tanelli, 2009: Rainfall retrieval over the ocean with spaceborne W-band radar. J. Geophys. Res., 114, D00A22, https:// doi.org/10.1029/2008JD009973. 
— T. T. Vonder Haar, T. L'Ecuyer, and D. Henderson, 2013: Radiative heating characteristics of Earth's cloudy atmosphere from vertically resolved active sensors. Geophys. Res. Lett., 40, 624-630, https://doi .org/10.1002/grl.50145.

Heidinger, A., Y. Li, B. A. Braum, R. E. Holz, S. Platnick, and P. Yang, 2015: Retrieval of cirrus cloud optical depth under day and night conditions from MODIS Collection 6 cloud property data. Remote Sens., 7, 7257-7271, https://doi.org/10.3390/rs70607257.

$\mathrm{Hu}, \mathrm{Y}$., and Coauthors, 2009: CALIPSO/CALIOP cloud phase discrimination algorithm. J. Atmos. Oceanic Technol., 26, 2293-2309, https://doi .org/10.1175/2009JTECHA1280.1.

Illingworth, A. J., and Coauthors, 2015: The EarthCare satellite: The next step forward in global measurements of clouds, aerosols, precipitation, and radiation. Bull. Amer. Meteor. Soc., 96, 1311-1332, https:// doi.org/10.1175/BAMS-D-12-00227.1.

Kahn, B. J., and Coauthors, 2014: The Atmospheric Infrared Sounder version 6 cloud products. Atmos. Chem. Phys., 14, 399-426, https://doi.org/10.5194 /acp-14-399-2014.

Kay, J. E., C. Wall, V. Yettella, B. Medeiros, C. Hannay, P. Caldwell, and C. Bitz, 2016: Global climate impacts of fixing the Southern Ocean shortwave radiation bias in the Community Earth System Model (CESM). J. Climate, 29, 4617-4636, https://doi.org/10.1175 /JCLI-D-15-0358.1.

Kox, S., L. Bugliaro, and A. Ostler, 2014: Retrieval of cirrus cloud optical thickness and top altitude from geostationary remote sensing. Atmos. Meas. Tech., 7, 3233-3246, https://doi.org/10.5194/amt-7-3233 -2014 .

Kulie, M. S., L. Milani, N. B. Wood, S. A. Tushaus, R. Bennartz, and T. S. L'Ecuyer, 2016: A shallow cumuliform snowfall census using spaceborne radar. $J$. Hydrometeor., 17, 1261-1279, https://doi.org/10.1175 /JHM-D-15-0123.1.

Kummerow, C., and Coauthors, 2000: The status of the Tropical Rainfall Measuring Mission (TRMM) after two years in orbit. J. Appl. Meteor., 39, 1965-1982, https://doi.org/10.1175/1520-0450(2001)040<1965: TSOTTR $>2.0 . \mathrm{CO} ; 2$.

L'Ecuyer, T., and Coauthors, 2015: The observed state of the energy budget in the early twenty-first century. J. Climate, 28, 8319-8346, https://doi.org/10.1175 /JCLI-D-14-00556.1.

Li, Z.-X., and H. Le Treut, 1992: Cloud-radiation feedback in a general circulation model and their dependence on cloud modeling assumptions. Climate Dyn., 7, 133-139, https://doi.org/10.1007 /BF00211155.
Liu, G., and E.-K. Seo, 2013: Detecting snowfall over land by satellite high-frequency microwave observations: The lack of scattering signature and a statistical approach. J. Geophys. Res. Atmos., 118, 1376-1387, https://doi.org/10.1002/jgrd.50172.

Liu, Z., and Coauthors, 2008: CALIPSO lidar observations of the optical properties of Saharan dust: A case study of long-range transport. J. Geophys. Res., 113, D07207, https://doi.org/10.1029/2007JD008878.

Mace, G. G., and F. Wrenn, 2013: Evaluation of the hydrometeor layers in the east and west Pacific within ISCCP cloud-top pressure-optical depth bins using merged CloudSat and CALIPSO data. J. Climate, 26, 9429-9444, https://doi.org/10.1175 /JCLI-D-12-00207.1.

—, and Q. Zhang, 2014: The CloudSat radarlidar geometrical profile product (RL-GeoProf): Updates, improvements, and selected results. $J$. Geophys. Res. Atmos., 119, 9441-9462, https://doi .org/10.1002/2013JD021374.

Mitchell, J. F. B., C. A. Senior, and W. J. Ingram, 1989: $\mathrm{CO}_{2}$ and climate: A missing feedback? Nature, 341, 132-134, https://doi.org/10.1038/341132a0.

National Research Council, 2015: Continuity of NASA Earth Observations from Space: A Value Framework. National Academies Press, 118 pp., https://doi .org/10.17226/21789.

O’Dell, C. W., F. J. Wentz, and R. Bennartz, 2008: Cloud liquid water path from satellite-based passive microwave observations: A new climatology over the global oceans. J. Climate, 21, 1721-1739, https://doi .org/10.1175/2007jcli1958.1.

Palerme, C., C. Genton, C. Chaud, J. E. Kay, N. B. Wood, and T. L'Ecuyer, 2017: Evaluation of current and projected Antarctic precipitation in CMIP5 models. Climate Dyn., 48, 225-239, https://doi.org/10.1007 /s00382-016-3071-1.

Rossow, W. B., and R. A. Schiffer, 1999: Advances in understanding clouds from ISCCP. Bull. Amer. Meteor. Soc., 80, 2261-2288, https://doi.org/10.1175 /1520-0477(1999)080<2261:AIUCFI>2.0.CO;2.

Simmons, A., and Coauthors, 2016: Observation and integrated Earth-system science: A roadmap for 2016-2025. Adv. Space Res., 57, 2037-2103, https:// doi.org/10.1016/j.asr.2016.03.008.

Smalley, M., T. L'Ecuyer, M. Lebsock, and J. Haynes, 2014: A comparison of precipitation occurrence from the NCEP Stage IV QPE product and the CloudSat Cloud Profiling Radar. J. Hydrometeor., 15, 444-458, https://doi.org/10.1175/JHM-D-13-048.1.

Stephens, G. L., and Coauthors, 2002: The CloudSat mission and the A-Train: A new dimension of spacebased observations of clouds and precipitation. 
Bull. Amer. Meteor. Soc., 83, 1771-1790, https://doi .org/10.1175/BAMS-83-12-1771.

—, and Coauthors, 2008: CloudSat mission: Performance and early science after the first year of operation. J. Geophys. Res., 113, D00A18, https://doi .org/10.1029/2008JD009982.

— balance in light of the latest global observations. Nat. Geosci., 5, 691-696, https://doi.org/10.1038/ngeo1580.

Stubenrauch, C. J., S. Cros, N. Lamquin, R. Armante, A. Chédin, C. Crevoisier, and N. A. Scott, 2008: Cloud properties from Atmospheric Infrared Sounder and evaluation with Cloud-Aerosol Lidar and Infrared Pathfinder Satellite Observations. J. Geophys. Res., 113, D00A10, https://doi.org/10.1029/2008JD009928.

Suzuki, K., T. Y. Nakajima, and G. L. Stephens, 2010: Particle growth and drop collection efficiency of warm clouds as inferred from joint CloudSat and MODIS observations. J. Atmos. Sci., 67, 3019-3032, https://doi.org/10.1175/2010JAS3463.1.

Takahashi, H., K. Suzuki, and G. L. Stephens, 2017: Landocean differences in the warm rain formation process in satellite observations, ground-based observations, and model simulations. Quart. J. Roy. Meteor. Soc., 143, 1804-1815, https://doi.org/10.1002/qj.3042.
Tan, I., T. Storelvmo, and M. D. Zelinka, 2016: Observational constraints on mixed-phase clouds imply higher climate sensitivity. Science, 352, 224227, https://doi.org/10.1126/science.aad5300.

Trenberth, K. E., and J. T. Fasullo, 2010: Simulation of present-day and twenty-first-century energy budgets of the southern oceans. J. Climate, 23, 440-454, https://doi.org/10.1175/2009JCLI3152.1.

Winker, D. M., and Coauthors, 2010: The CALIPSO Mission: A global 3D view of aerosols and clouds. Bull. Amer. Meteor. Soc., 91, 1211-1229, https://doi .org/10.1175/2010BAMS3009.1.

—, J. L. Tackett, B. J. Getzewich, Z. Liu, M. A. Vaughan, and R. R. Rogers, 2013: The global 3-D distribution of tropospheric aerosols as characterized by CALIOP. Atmos. Chem. Phys., 13, 3345-3361, https://doi.org/10.5194/acp-13-3345-2013.

Yumimoto, K., K. Eguchi, I. Uno, T. Takemura, Z. Liu, A. Shimizu, and N. Sugimoto, 2009: Elevated largescale dust veil originated in the Taklimakan Desert: Intercontinental transport and 3-dimensional structure captured by CALIPSO and regional and global models. Atmos. Chem. Phys., 9, 8545-8558, https:// doi.org/10.5194/acp-9-8545-2009.

\section{NEW FROM AMS BOOKS!}

\section{A Scientific Peak: How Boulder Became a World Center for Space and Atmospheric Science}

\section{Joseph P. Bassi}

nce a Wild West city tucked between the Rocky Mountains and the Great Plains, Boulder is now home to some of the biggest names in science, including NCAR, NOAA, and NIST.

Why did big science come to Boulder? How did Boulder become the research mecca it is today?

A Scientific Peak is a fascinating history that introduces us to a wide variety of characters, such as Walter Orr Roberts, and the serendipitous brew of politics, passion, and sheer luck that, during the post-WWII and Cold War eras, transformed this "scientific Siberia" into one of America's smartest cities.

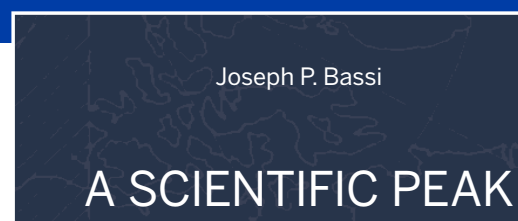

(C) 2015, 264 pages, paperback

print ISBN: 978-1-935704-85-0 eISBN: 978-1-940033-89-1 List price: $\$ 35$ AMS Member price: $\$ 25$ 


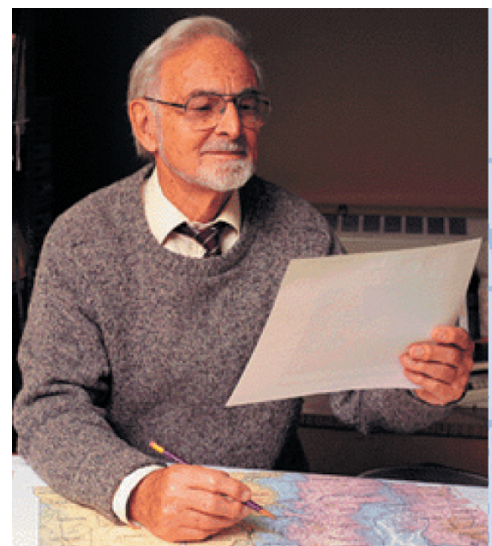

A Half Century of Progress in Meteorology:

A Tribute to Richard Reed

\section{edited by Richard H. Johnson and Robert A. Houze Jr.}

with selections by: Lance F. Bosart Robert W. Burpee Anthony Hollingsworth James R. Holton Brian J. Hoskins Richard S. Lindzen John S. Perry Erik A. Rasmussen Adrian Simmons Pedro Viterbo

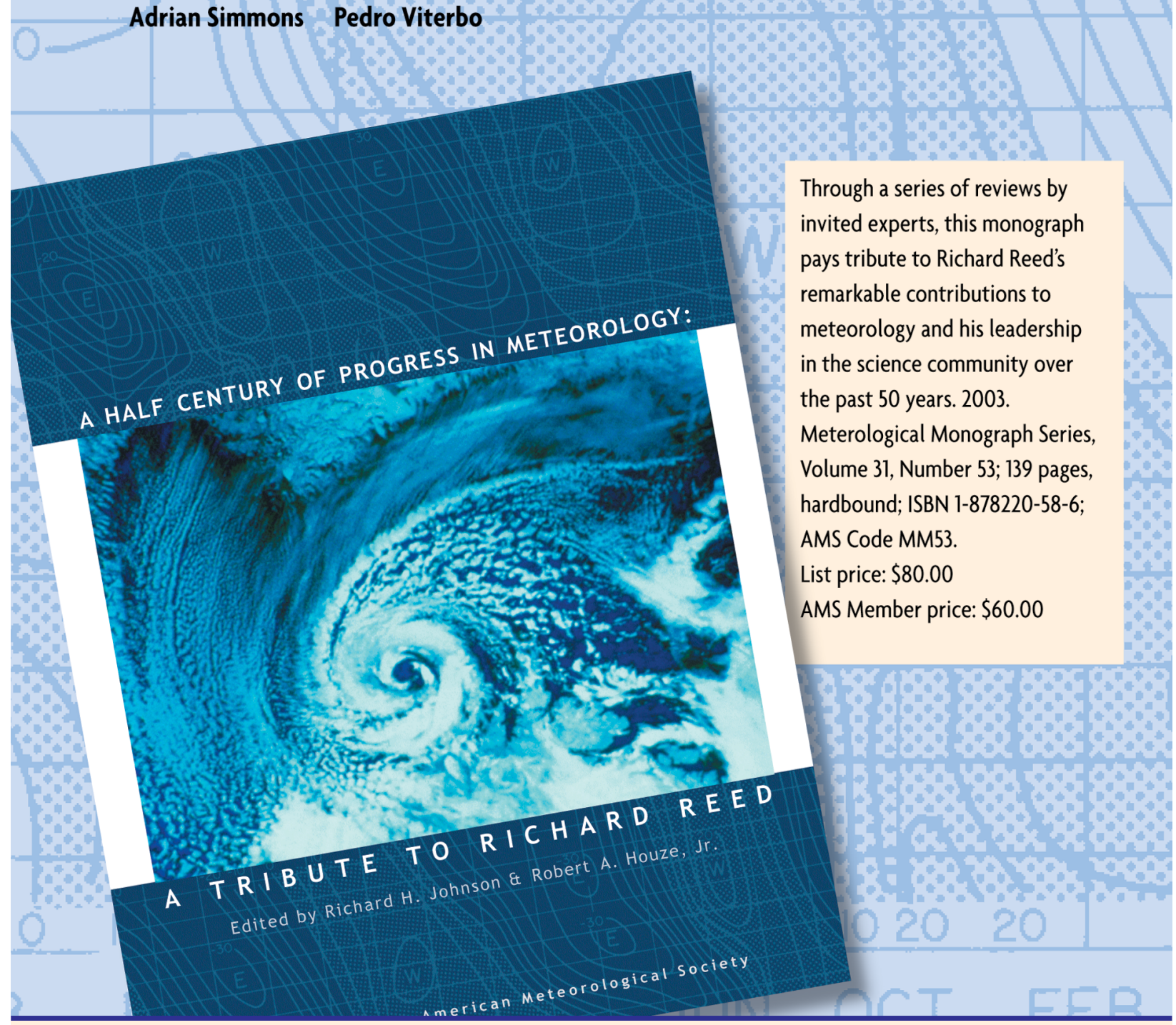

Order Online from bookstore.ametsoc.org 